\title{
Overall survival and disease-free survival in endometrial cancer: prognostic factors in 276 patients
}

This article was published in the following Dove Press journal:

OncoTargets and Therapy

13 September 2013

Number of times this article has been viewed

\author{
Álvaro Tejerizo-García' \\ Jesús S Jiménez-López' \\ José L Muñoz-González' \\ Sara Bartolomé-Sotillos' \\ Laura Marqueta-Marqués' \\ Gregorio López-González' \\ José $\mathrm{F}$ Pérez-Regadera \\ Gómez ${ }^{2}$
}

'Service of Obstetrics and Gynecology, ${ }^{2}$ Radiation Oncology Service, Hospital Universitario 12 de Octubre, Madrid, Spain
Objective: The aim of the study reported here was to assess the disease-free survival and overall survival of patients with endometrial cancer and to determine independent factors affecting the prognosis.

Materials and methods: This was a retrospective study of a single-center clinical series of 276 patients (mean age 64 years) with histologically confirmed cancer of the corpus uteri. The standard treatments were extrafascial total hysterectomy and bilateral salpingo-oophorectomy with selective pelvic/para-aortic node dissection, according to risk for recurrence. Actuarial overall survival and disease-free survival were estimated according to the Kaplan-Meier method. Univariate and multivariate Cox proportional hazards analyses were used to assess the prognostic significance of the different variables.

Results: The estimated median follow-up, determined using the inverse Kaplan-Meier method, was 45 months ( $95 \%$ confidence interval [CI] 41.2-48.8) for disease-free survival and 46 months (95\% CI 43.0-49.0) for overall survival. The statistically significant variables affecting diseasefree survival and overall survival were age, serous-papillary and clear-cell histological types, outer-half myometrial invasion, advanced International Federation of Gynecology and Obstetrics (FIGO) stage, tumor grades G2 and G3, incomplete surgical resection, positive lymph nodes, lymphovascular space invasion, tumor remnants of $>1 \mathrm{~cm}$ after surgery, and high-risk group. In the multivariate Cox regression model, predictors of tumor recurrence included advanced FIGO stage (hazard ratio [HR] 4.90, 95\% CI 2.57-9.36, $P<0.001$ ) and tumor grades G2 (HR 4.79, 95\% CI 1.73-13.27, $P=0.003$ ) and G3 (HR 7.56, 95\% CI 2.75-20.73, $P<0.001$ ). The same variables were also associated with a significantly higher risk of tumor-related mortality.

Conclusion: FIGO stage and tumor grade were independent prognostic factors of disease-free survival and overall survival in endometrial cancer patients. Outcome was also influenced by histopathologic type, myometrial and lymphovascular space invasion, lymph-node involvement, age, and tumor remnants after surgery, although a larger study sample is probably needed to demonstrate the independent association of these variables with survival.

Keywords: FIGO stage, tumor grade, lymph-node involvement, tumor remnant, recurrence, myometrial invasion

\section{Introduction}

Endometrial cancer remains the most common gynecologic malignancy in Western Europe and the USA, with an estimated lifetime risk of $2.6 \%$ for women living in developed nations, and a median age at diagnosis of 61 years. ${ }^{1}$ In contrast to the progress observed with many other cancer types, the incidence of endometrial cancer has increased over the past 30 years. ${ }^{2,3}$ This is in part related to the current epidemic of obesity, which is strongly linked to risk of endometrial cancer. ${ }^{4}$ Fortunately, the
Correspondence: Jesús S Jiménez-López Service of Obstetrics and Gynecology, Hospital Universitario 12 de Octubre, Avenida de Córdona s/n, E-2804 I

Madrid, Spain

Tel/Fax +34 9l 3908376

Email jjimenez.hdoc@salud.madrid.org 
majority of women with endometrial cancer are diagnosed at an early stage (the disease is confined to the uterine corpus) and may be cured by surgery with or without adjuvant radiotherapy. Roughly $75 \%$ of women survive for 5 years. ${ }^{5,6}$

A wide variety of prognostic factors for survival among them, histological type, International Federation of Gynecology and Obstetrics (FIGO) stage, tumor grade, depth of myometrial invasion, lymphovascular space invasion, peritoneal cytology, and age at the time of diagnosis - have been described and extensively evaluated in the literature. ${ }^{7-13}$ However, only a few studies performed multivariate analysis and obtained different results on their significance. ${ }^{14,15}$ Also, the anatomical extent of lymphadenectomy and the number of lymph nodes that need to be removed to establish prognostic and therapeutic benefit are controversial. ${ }^{4}$

The objective of this study was to assess overall survival and disease-free survival of a clinical series of 276 patients with endometrial cancer and to determine multivariate independent factors affecting the prognosis of patients with carcinoma of the endometrium.

\section{Materials and methods}

Between January 2001 and December 2007, 358 consecutive patients were referred to the Service of Obstetrics and Gynecology of University Hospital October 12, in Madrid, Spain, to be treated for histologically confirmed cancer of the corpus uteri. The standard surgical treatments were extrafascial total hysterectomy and bilateral salpingo-oophorectomy with selective pelvic/para-aortic node dissection, according to risk for recurrence (intermediate risk: FIGO stage IA tumor grade [G] 3 IB G3, IC G1-2 and II [occult]; high risk: IC G3, II, III, and serous-papillary or clear-cell types). Clinical stages and pathological grading were reviewed according to the FIGO classification (1988). Tumor grade was evaluated including architectural and nuclear grade.

Adjuvant treatment was discussed in multidisciplinary team meetings with radiotherapists, pathologists, and medical oncologists. External-beam radiotherapy was indicated in FIGO stages IB or IC G3, IIA G3, and greater than IIB, in combination with endocavitary radiotherapy in stages $\geq$ IB G3. Adjuvant chemotherapy was used in highrisk patients (stages III and IV).

Initial surgical staging was considered incomplete in surgical stages $\geq$ IC without lymphadenectomy, G3 without lymphadenectomy (except for stage IA) and unfavorable histological subtypes (serous-papillary, clear cell, undifferentiated) without lymphadenectomy. Incomplete surgical resection was defined in the presence of incomplete tumor removal (tumor remnant $>1 \mathrm{~cm}$ ) and/or incomplete surgical staging.

Patients were followed-up with clinical, cytological, analytical, and radio-imaging studies every 3 months for the first 2 years, then every 6 months for the third, fourth and fifth year, and then every year following for up to 10 years. The analyzed prognostic variables included patient age, obesity (body mass index $[\mathrm{BMI}] \geq 30 \mathrm{~kg} / \mathrm{m}^{2}$ ), tumor histology, myometrial invasion, FIGO stage, tumor grade, incomplete surgical resection, tumor remnant $>1 \mathrm{~cm}$, lymphovascular space invasion, surgical approach (laparotomy vs laparoscopy), performance of lymphadenectomy prior to identification of risk groups, and high risk for recurrence. Disease-free survival and overall survival were calculated from the date of surgery.

\section{Statistical analysis}

Statistical analysis was performed using SPSS (v 15.0; IBM, Armonk, NY, USA). Actuarial overall survival and diseasefree survival were estimated according to the Kaplan-Meier method and the significance between curves by the log-rank test. Univariate Cox proportional hazards analysis was used to assess the prognostic significance of the different characteristics. Multivariate analysis using the Cox regression model was also performed. According to criteria for clinical relevance, three significant variables at univariate testing (histological type, FIGO stage, tumor grade) were included in the Cox regression model. Risk for recurrence and death are expressed as the hazard ratio (HR) with the $95 \%$ confidence interval (CI). A $P$-value of $<0.05$ was considered statistically significant.

\section{Results}

A total of 358 patients with endometrial cancer were reviewed in the study period, but $82(22.9 \%)$ of these were excluded from the analysis because they had inoperable tumors or their follow-up was unable to be completed as treatment was undertaken in other centers. Therefore, the study population consisted of 276 patients, with a mean (standard deviation [SD]) age of 64 (11) years and a mean BMI of $30.8(6.1) \mathrm{kg} / \mathrm{m}^{2}$. The BMI was $\geq 30 \mathrm{~kg} / \mathrm{m}^{2}$ in 31 patients. Of the women, $87 \%(n=241)$ of the women were menopausal. History of breast cancer was recorded in 30 patients (treatment with tamoxifen in 25) and of colorectal cancer in four.

Briefly, surgical treatment included standard total hysterectomy and bilateral salpingo-oophorectomy in 274 patients (laparotomy in 82 and laparoscopy in 192) 
and radical hysterectomy in two. Pelvic and/or para-aortic lymphadenectomy was performed in 150 patients, with negative histological findings in 137 (91.3\%) and positive in $13(8.7 \%)$. Lymphadenectomy was more common with laparoscopy than with laparotomy (55.2\% vs 51.2\%). Half $(50 \%)$ of the patients received adjuvant radiotherapy and $3.2 \%$ platine-based chemotherapy.

Table 1 shows the surgical stage, grade, and histological condition of the endometrial cancers. The most frequent characteristics were endometrioid carcinoma $(84.8 \%$ of cases), G1 (48.9\%) and stages IB (35.1\%) and IC (23.2\%). Myometrial infiltration $<50 \%$ was documented in $39.1 \%$ of cases and $>50 \%$ in $31.2 \%$. Lymphovascular space invasion was found in $11.9 \%$ of cases. Peritoneal cytology was

Table I Characteristics of endometrial tumors in 276 patients

\begin{tabular}{|c|c|}
\hline Characteristic & Patients, n (\%) \\
\hline \multicolumn{2}{|l|}{ Histological type } \\
\hline Endometrioid & $234(84.8)$ \\
\hline Serous-papillary & $19(6.9)$ \\
\hline Clear cell & $7(2.5)$ \\
\hline Other & $16(5.8)$ \\
\hline \multicolumn{2}{|l|}{ Tumor grade } \\
\hline GI & $135(48.9)$ \\
\hline G2 & $78(28.3)$ \\
\hline G3 & $63(22.8)$ \\
\hline \multicolumn{2}{|l|}{ FIGO stage } \\
\hline IA & $74(26.8)$ \\
\hline IB & $97(35.1)$ \\
\hline IC & $64(23.2)$ \\
\hline IIA & $9(3.3)$ \\
\hline IIB & $8(2.9)$ \\
\hline IIIA & $10(3.6)$ \\
\hline IIIC & $12(4.3)$ \\
\hline IV & I $(0.4)$ \\
\hline IVB & $\mathrm{I}(0.4)$ \\
\hline \multicolumn{2}{|l|}{ Myometrial invasion } \\
\hline Only endometrium & $79(28.6)$ \\
\hline Inner half $(<50 \%)$ & $108(39.1)$ \\
\hline Outer half $(>50 \%)$ & $86(31.2)$ \\
\hline Uterine serosal involvement & $3(1.1)$ \\
\hline \multicolumn{2}{|l|}{ Lymphovascular invasion } \\
\hline Focal & $9(3.3)$ \\
\hline Frank & $24(8.7)$ \\
\hline Absent & $215(77.9)$ \\
\hline Unknown & $28(10.1)$ \\
\hline \multicolumn{2}{|l|}{ Peritoneal cytology } \\
\hline Negative & $251(91.3)$ \\
\hline Positive & $8(2.9)$ \\
\hline Doubtful & I $(0.4)$ \\
\hline Unknown & $15(5.5)$ \\
\hline \multicolumn{2}{|l|}{ Risk for recurrence } \\
\hline Low & $145(52.5)$ \\
\hline Intermediate & $59(21.4)$ \\
\hline High & $72(26.1)$ \\
\hline
\end{tabular}

Abbreviation: FIGO, International Federation of Gynecology and Obstetrics. negative in $91.3 \%$ of cases. Incomplete surgical staging was recorded in 23 patients; this was due to age over 80 years in eight, sub-staging in the extension study in eight, intraoperative difficulties preventing to perform the complete surgical protocol in five, and morbid obesity in two. In two patients (stages III-IV), tumor remnants $>1 \mathrm{~cm}$ were left. After surgery, $52.5 \%$ of patients were classified into the low-risk (of recurrence) group, $21.4 \%$ into the intermediate-risk group, and $26.1 \%$ into the high-risk group.

The disease-free 5-year survival was $82.3 \%$ and the overall 5-year survival was $81 \%$ (Figure 1 ). The tumor recurrence rate was $14.5 \%(\mathrm{n}=40)$ and the tumor-related mortality rate $15.9 \%(n=44)$. The estimated median follow-up using the inverse Kaplan-Meier method was 45 months (95\% CI 41.2-48.8) for disease-free survival and 46 months $(95 \%$ CI 43.0-49.0) for overall survival. As shown in Table 2, prognostic variables significantly affecting disease-free survival and overall survival included FIGO stages II, III, and IV; non-endometrioid tumor type; G2 and G3; outer-half myometrial invasion; incomplete surgical treatment; tumor remnant $>1 \mathrm{~cm}$; positive nodes; lymphovascular invasion; and intermediate- and high-risk groups. Differences in disease-free survival and overall survival in terms of FIGO stage and tumor grade are shown in Figure 2 and Table 3 and Figure 3 and Table 4, respectively.
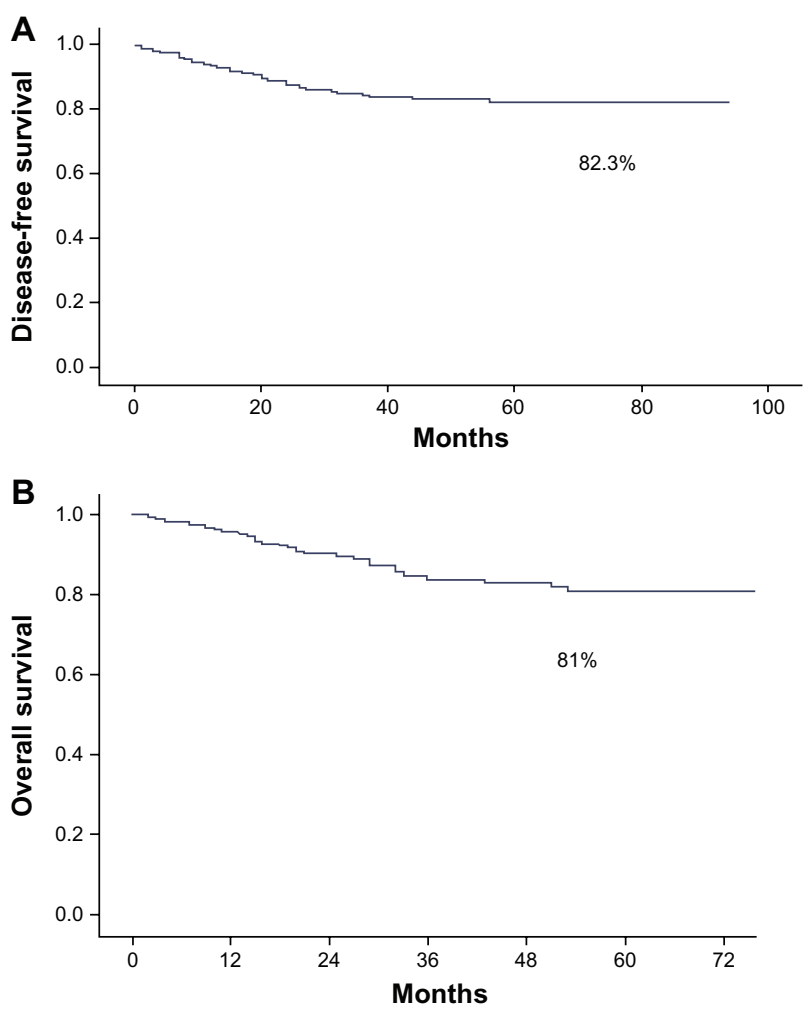

Figure I (A) Disease-free survival and (B) overall survival in the study population. 
Table 2 Disease-free survival and overall survival at 5 years for the variables analyzed

\begin{tabular}{|c|c|c|c|c|}
\hline \multirow[t]{2}{*}{ Variables } & \multicolumn{2}{|c|}{ Disease-free survival } & \multicolumn{2}{|c|}{ Overall survival } \\
\hline & Percentage & $P$-value* & Percentage & $P$-value \\
\hline \multicolumn{5}{|l|}{ Age, years } \\
\hline$<50$ & 95.5 & Ref & 90.9 & Ref \\
\hline $50-70$ & 86 & 0.254 & 88.1 & 0.450 \\
\hline$>70$ & 81.3 & 0.113 & 72.2 & 0.324 \\
\hline \multicolumn{5}{|l|}{ FIGO stage } \\
\hline Local (stage I) & 91.0 & Ref & 90.2 & Ref \\
\hline Advanced (stages II-IV) & 52.2 & $<0.001$ & 48.8 & $<0.001$ \\
\hline \multicolumn{5}{|l|}{ Histological type } \\
\hline Endometrioid & 89.6 & Ref & - & Ref \\
\hline Non-endometrioid & 61.9 & $<0.001$ & 66.7 & 0.0001 \\
\hline \multicolumn{5}{|l|}{ Tumor grade } \\
\hline GI & 96.3 & Ref & 95.6 & Ref \\
\hline $\mathrm{G} 2$ & 80.8 & $<0.00 \mathrm{I}$ & 82.1 & 0.001 \\
\hline G3 & 66.7 & $<0.001$ & 61.9 & $<0.001$ \\
\hline \multicolumn{5}{|l|}{ Myometrial invasion } \\
\hline No & 86.5 & Ref & 87.4 & Ref \\
\hline Yes & 81.4 & 0.002 & 42.9 & $<0.001$ \\
\hline \multicolumn{5}{|c|}{ Incomplete surgical treatment } \\
\hline No & 86.5 & Ref & 87.4 & Ref \\
\hline Yes & 81.4 & 0.002 & 42.9 & $<0.001$ \\
\hline \multicolumn{5}{|l|}{ Tumor remnant $>I \mathrm{~cm}$} \\
\hline No & 86.2 & Ref & 85.2 & Ref \\
\hline Yes & 40.0 & $<0.001$ & 20.0 & $<0.001$ \\
\hline \multicolumn{5}{|l|}{ Lymph node involvement } \\
\hline Negative & 88.7 & Ref & 89.8 & Ref \\
\hline Positive & 41.7 & $<0.001$ & 38.5 & $<0.001$ \\
\hline Not determined & 80.1 & 0.701 & 82.5 & 0.034 \\
\hline \multicolumn{5}{|c|}{ Lymphovascular space invasion } \\
\hline Negative & 88.9 & Ref & 89.3 & Ref \\
\hline Focal & - & - & 66.7 & 0.353 \\
\hline Frank & 41.7 & $<0.00$ I & 50.0 & $<0.001$ \\
\hline \multicolumn{5}{|l|}{ Surgical approach } \\
\hline Laparotomy & 80.0 & Ref & 80.2 & Ref \\
\hline Laparoscopy & 87.7 & 0.110 & 87.2 & 0.153 \\
\hline \multicolumn{5}{|c|}{ Pelvic/Para-aortic lymphadenectomy } \\
\hline No & 88.7 & Ref & 82.5 & Ref \\
\hline Yes & 82.6 & 0.233 & 85.3 & 0.340 \\
\hline \multicolumn{5}{|l|}{ Risk group for recurrence } \\
\hline Low & 95.9 & Ref & 95.2 & Ref \\
\hline Intermediate & 87.7 & $<0.00 \mathrm{I}$ & 83.1 & 0.003 \\
\hline High & 62.0 & $<0.001$ & 62.5 & 0.0016 \\
\hline
\end{tabular}

Note: *Log-rank test.

Abbreviations: FIGO, International Federation of Gynecology and Obstetrics; ref, reference category.

In the Cox univariate analysis (Table 5), statistically significant variables affecting disease-free survival and overall survival were age, serous-papillary and clear-cell histological types, outer-half myometrial invasion, advanced FIGO stage, G2 and G3, incomplete surgical resection, positive lymph nodes, lymphovascular space invasion, tumor remnant $>1 \mathrm{~cm}$, and high-risk group. In the multivariate Cox regression model, predictors of tumor recurrence included advanced FIGO stage (HR 4.90, 95\% CI 2.57-9.36, $P<0.001$ ) and grades G2 (HR 4.79, 95\% CI 1.73-13.27, $P=0.003)$ and G3 (HR 7.56, 95\% CI 2.75-20.73, $P<0.001$ ). The same variables were also associated with a significantly higher risk of tumor-related mortality, with a HR of 4.90 (95\% CI 2.57-9.36, $P<0.001)$ for advanced FIGO stage, HR of $3.54(95 \% \mathrm{CI} 1.35-931, P=0.01)$ for $\mathrm{G} 2$, and HR of 6.76 (95\% CI 2.65-17.13, $P<0.001)$ for G3. 

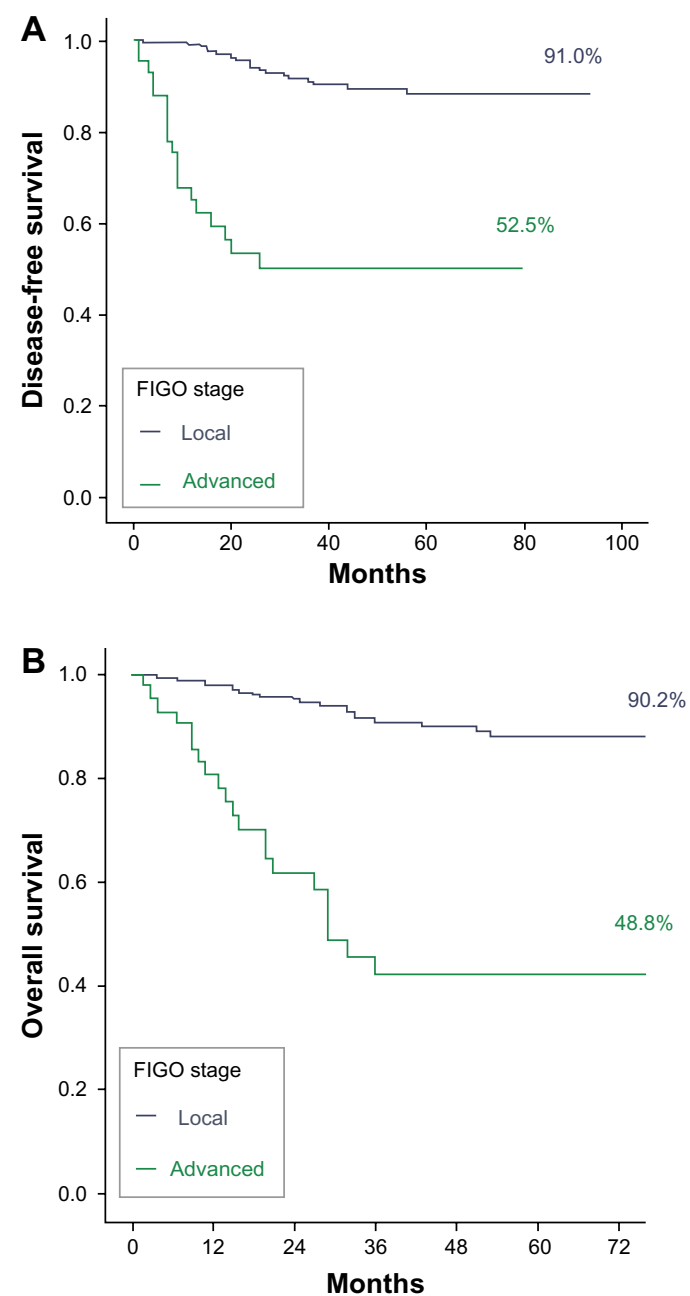

Figure 2 Differences in (A) disease-free survival and (B) overall survival between local and advanced International Federation of Gynecology and Obstetrics (FIGO) stages.

\section{Discussion}

In the series of 276 patients with carcinoma of the endometrium, the 5 -year disease-free survival was $82.3 \%$, which is similar to data reported by other authors. ${ }^{8,14,15}$ Also, the 5-year overall survival of $81 \%$ found in our study is similar to the $80 \%$ found by Creasman et $\mathrm{al}^{5}$ in a study of 8,110 patients.

Table 3 Differences in disease-free survival and overall survival according to International Federation of Gynecology and Obstetrics (FIGO) stage

\begin{tabular}{llll}
\hline FIGO stage & N (\%) & Total & P-value \\
\hline Disease-free survival & & & \\
$\quad$ Local (stage I) & 2 I (9.0) & 233 & $<0.00$ I \\
$\quad$ Advanced (stage II-IV) & $19(47.5)$ & 40 & \\
Overall survival & & & \\
$\quad$ Local (stage I) & $23(9.8)$ & 235 & $<0.00$ I \\
$\quad$ Advanced (stage II-IV) & $21(5 I .2)$ & $4 \mathrm{I}$ & \\
\hline
\end{tabular}
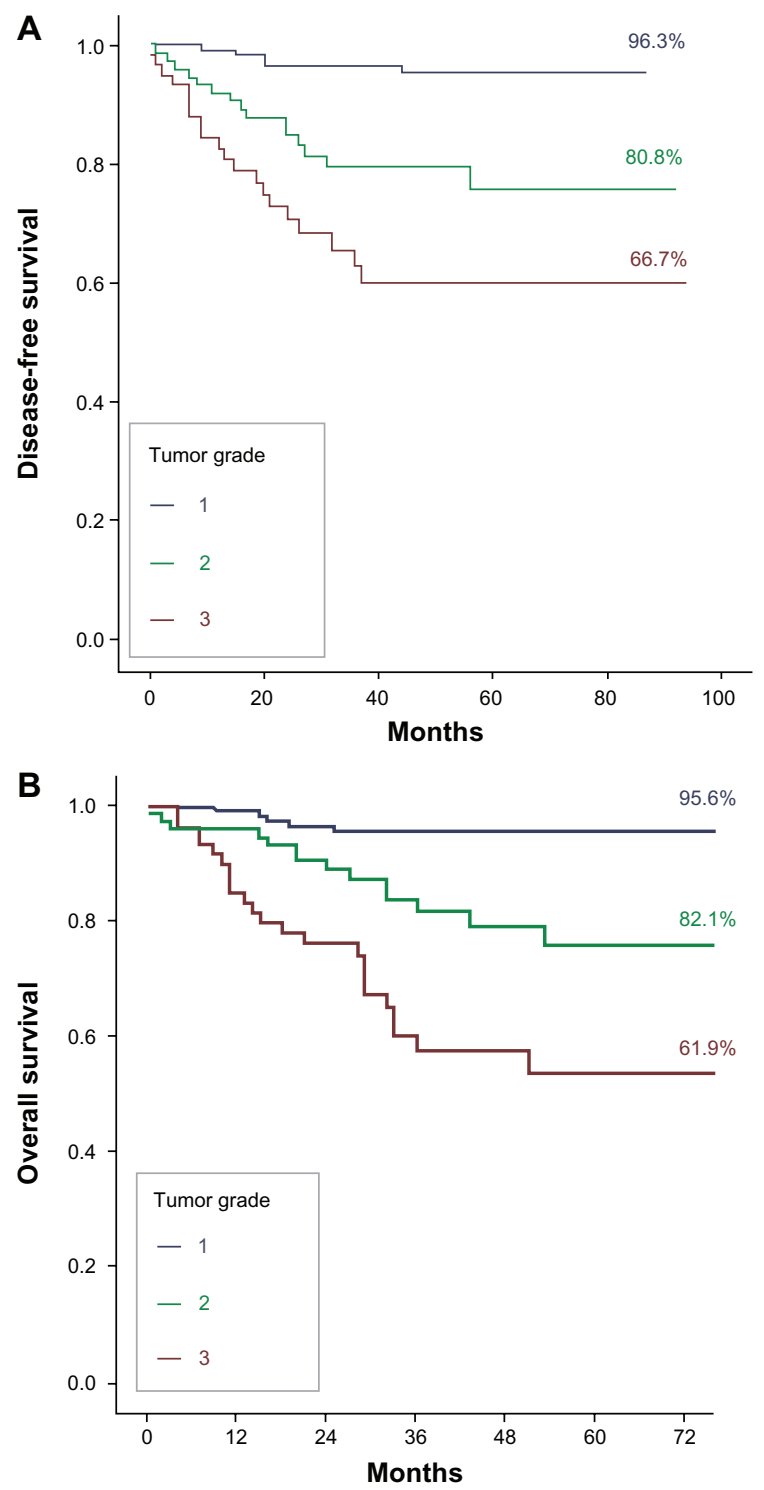

Figure 3 Differences in (A) disease-free survival and (B) overall survival according to tumor grade.

In relation to prognostic factors, in our study, as in others, ${ }^{8,12,14}$ FIGO stage was significantly associated with tumor recurrence and mortality. Disease-free survival at 5 years was $91 \%$ for patients with FIGO stage I cancer as compared with $52.5 \%$ for those with FIGO stage II, III, or IV. This difference was statistically significant. The influence of FIGO stage on the outcome of patients with endometrial cancer was confirmed in the multivariate analysis, in which it was demonstrated that the probability of tumor recurrence was 7.5 times higher in patients with FIGO stage II, III, or IV than in those with FIGO stage I. Moreover, the probability of survival was influenced by FIGO stage, which was also demonstrated by Kosary ${ }^{9}$ in an analysis of data on 41,120 cases of endometrial cancer, obtained from the National 
Table 4 Differences in disease-free survival and overall survival according to tumor grade

\begin{tabular}{llll}
\hline Tumor grade & N (\%) & Total & P-value \\
\hline $\begin{array}{llll}\text { Disease-free survival } \\
\text { Grade I }\end{array}$ & $5(3.7)$ & 135 & $\begin{array}{l}\text { Reference } \\
\text { Grade 2 }\end{array}$ \\
I5 (19.2) & 78 & $<0.00 \mathrm{I}$ \\
Grade 3 & $20(33.3)$ & 60 & $<0.00 \mathrm{I}^{*}$ \\
& & & $0.039^{* *}$ \\
Overall survival & & & Reference \\
Grade I & $6(4.4)$ & 135 & $<0.00 \mathrm{I}$ \\
Grade 2 & $14(17.9)$ & 78 & $<0.00 I^{*}$ \\
Grade 3 & $24(38.1)$ & 63 & $0.005^{* *}$ \\
\hline
\end{tabular}

Notes: $* P<0.001 ; * * P<0.005$.
Cancer Institute's Surveillance, Epidemiology, and End Results (SEER) program, that were diagnosed between 1973 and 1987. The overall survival rate at 5 years was $48.8 \%$ in patients with advanced stages in contrast to $90.2 \%$ in patients with early disease. In agreement with data reported by Steiner et $\mathrm{al}^{15}$ and Creasman et al, ${ }^{5}$ FIGO stage was an independent predictor of survival. Patients with advanced disease showed a 4.95-times-higher probability of death than patients with stage I (Table 6).

The influence of the histopathologic tumor type as independent prognostic factor for recurrence-free survival and mortality was documented in a set of 181 patients

Table 5 Results of univariate Cox proportional hazards analysis: risk of tumor recurrence and overall mortality associated with the variables analyzed

\begin{tabular}{|c|c|c|c|c|}
\hline \multirow[t]{2}{*}{ Variable } & \multicolumn{2}{|l|}{ Tumor recurrence } & \multicolumn{2}{|l|}{ Overall mortality } \\
\hline & Hazard ratio $(95 \% \mathrm{Cl})$ & $P$-value & Hazard ratio $(95 \% \mathrm{Cl})$ & $P$-value \\
\hline Age, years & $1.05(1.02-1.09)$ & 0.002 & $1.07(1.04-1.10)$ & $<0.001$ \\
\hline \multicolumn{5}{|l|}{ Obesity, BMI > $30 \mathrm{~kg} / \mathrm{m}^{2}$} \\
\hline No & 1.00 & & 1.00 & \\
\hline Yes & $0.97(0.50-1.88)$ & 0.930 & $1.07(0.57-2.03)$ & 0.836 \\
\hline \multicolumn{5}{|l|}{ Histological type } \\
\hline Endometrioid & 1.00 & & 1.00 & \\
\hline Serous-papillary, clear cells & 5.01 (2.65-9.48) & $<0.00$ I & $3.39(1.79-6.43)$ & $<0.001$ \\
\hline \multicolumn{5}{|l|}{ Myometrial invasion } \\
\hline Inner half $(<50 \%)$ & 1.00 & & 1.00 & \\
\hline Outer half $(>50 \%)$ & $3.37(1.99-5.68)$ & $<0.001$ & $2.40(1.53-3.79)$ & $<0.001$ \\
\hline \multicolumn{5}{|l|}{ FIGO stage } \\
\hline Local (stage I) & 1.00 & & 1.00 & \\
\hline Advanced (stages II-IV) & $7.53(4.03-14.07)$ & $<0.00 \mathrm{I}$ & $7.88(4.29-14.47)$ & $<0.001$ \\
\hline \multicolumn{5}{|l|}{ Tumor grade } \\
\hline GI & 1.00 & & 1.00 & \\
\hline G2 & $5.78(2.10-15.91)$ & $<0.001$ & $4.39(1.69-11.44)$ & 0.001 \\
\hline G3 & II.53 (4.32-30.76) & $<0.001$ & $10.65(4.34-26.13)$ & $<0.001$ \\
\hline \multicolumn{5}{|c|}{ Pelvic/para-aortic lymphadenectomy } \\
\hline No & 1.00 & & 1.00 & \\
\hline Yes & $\mathrm{I} .48(0.77-2.84)$ & 0.233 & $0.75(0.4 \mathrm{I}-\mathrm{I} .36)$ & 0.340 \\
\hline \multicolumn{5}{|l|}{ Surgical approach } \\
\hline Laparoscopy & 1.00 & & 1.00 & \\
\hline Laparotomy abdominal & $1.67(0.88-3.17)$ & 0.115 & $1.58(0.84-2.97)$ & 0.158 \\
\hline \multicolumn{5}{|l|}{ Incomplete surgical treatment } \\
\hline No & 1.00 & & 1.00 & \\
\hline Yes & $3.55(1.48-8.48)$ & 0.002 & $6.75(3.43-13.29)$ & $<0.001$ \\
\hline \multicolumn{5}{|l|}{ Lymph-node involvement } \\
\hline Negative & 1.00 & & 1.00 & \\
\hline Positive & $1.77(1.05-2.99)$ & 0.032 & $3.01(1.83-4.95)$ & $<0.001$ \\
\hline \multicolumn{5}{|l|}{ Lymphovascular space invasion } \\
\hline No & 1.00 & & 1.00 & \\
\hline Yes & $4.81(2.54-9.13)$ & $<0.001$ & $3.81(2.04-7.13)$ & $<0.001$ \\
\hline \multicolumn{5}{|l|}{ Tumor remnant $>1 \mathrm{~cm}$} \\
\hline No & 1.00 & & 1.00 & \\
\hline Yes & $5.18(1.59-18.83)$ & 0.006 & $6.21(2.21-17.44)$ & 0.001 \\
\hline \multicolumn{5}{|l|}{ Risk group for recurrence } \\
\hline Low & 1.00 & & 1.00 & \\
\hline Intermediate & $5.24(0.68-40.62)$ & 0.113 & $6.54(0.86-49.58)$ & 0.069 \\
\hline High & $3 I .4 I(4.27-23 I .3)$ & 0.001 & 28.27 (3.84-208.27) & 0.001 \\
\hline
\end{tabular}

Abbreviations: $\mathrm{Cl}$, confidence interval; BMI, body mass index; FIGO, International Federation of Gynecology and Obstetrics. 
Table 6 Results of multivariate Cox proportional hazards analysis for International Federation of Gynecology and Obstetrics (FIGO) stage and tumor grade

\begin{tabular}{|c|c|c|c|c|}
\hline & \multicolumn{2}{|c|}{ Disease-free survival } & \multicolumn{2}{|c|}{ Overall survival } \\
\hline & $\begin{array}{l}\text { Hazard ratio } \\
(95 \% \mathrm{Cl})\end{array}$ & $P$-value & $\begin{array}{l}\text { Hazard ratio } \\
(95 \% \mathrm{Cl})\end{array}$ & $P$-value \\
\hline \multicolumn{5}{|l|}{ FIGO stage } \\
\hline Local & 1.00 & $<0.001$ & 1.00 & $<0.00 \mathrm{I}$ \\
\hline Advanced & $\begin{array}{l}4.90 \\
(2.57-9.36)\end{array}$ & & $\begin{array}{l}4.95 \\
(2.63-9.32)\end{array}$ & \\
\hline \multicolumn{5}{|l|}{ Tumor grade } \\
\hline GI & 1.00 & 0.002 & 1.00 & 0.010 \\
\hline G2 & $\begin{array}{l}4.79 \\
(1.73-13.27)\end{array}$ & $<0.001$ & $\begin{array}{l}3.54 \\
(1.35-9.31)\end{array}$ & $<0.001$ \\
\hline G3 & $\begin{array}{l}7.56 \\
(2.75-20.73)\end{array}$ & & $\begin{array}{l}6.76 \\
(2.67-17.13)\end{array}$ & \\
\hline
\end{tabular}

Abbreviation: $\mathrm{Cl}$, confidence interval.

with endometrial cancer described by Steiner et al. ${ }^{15}$ These authors reported a significantly increased overall survival and recurrence-free survival for patients with adenocarcinoma or adenoacanthoma as compared to other tumor types (papillary, clear-cell carcinoma, and others). In our study, patients with endometrioid tumors had a disease-free survival rate of $89.6 \%$, which was significantly higher than the $61.9 \%$ for patients with other tumor types, such as serous-papillary, clear cell, and undifferentiated carcinomas. Moreover, the probability of tumor recurrence was five times higher for serous-papillary and clear-cell types than for endometrioid tumors, although the probability of death was also 3.39 times higher for unfavorable tumor types. However, histopathologic tumor type was not selected in the regression model for either tumor recurrence or mortality, which may be explained by the low number of events in our series (40 cases of tumor relapse and 40 deaths), limiting the statistical power of the analysis.

Degree of tumor differentiation has been shown to affect survival in endometrial cancer, although it is difficult to determine the impact of this factor as an independent prognostic variable because of the close relationship with other factors. Creasman et $\mathrm{al}^{5}$ showed that poorly differentiated tumors had a higher risk of myometrial invasion and, therefore, lymph-node metastasis. Hanson et $\mathrm{al}^{16}$ analyzed the surgical specimens of 111 patients with stage I endometrial cancer. Lymphovascular space invasion was noted in 16 cases, and occurred most frequently in poorly differentiated tumors with deep myometrial penetration. Malignant peritoneal cytology has been also associated with $\mathrm{G} 3$ tumors. ${ }^{17}$ In our study, tumor grading was a significant predictor of outcome in the univariate and multivariate analyses. The probability of disease-free survival at 5 years decreased from $96.3 \%$ in G1 endometrial carcinoma to $80.8 \%$ in G2 and $66.7 \%$ in G3. Similarly, overall survival was $95.6 \%$ in $\mathrm{G} 1,82.1 \%$ in G2, and $61.9 \%$ in G3. Patients with G2 showed 5.8-timeshigher risk for tumor recurrence than patients with early endometrial cancer, which increased to 11.5 times in patients with G3 endometrial carcinoma (Table 6). The unfavorable effect of poorly differentiated tumors on survival was similar. Steiner et a ${ }^{15}$ also reported a significant association between tumor grade and disease-free interval and overall survival. In Reisinger et al's ${ }^{18}$ study of 51 patients with stage II endometrial cancer, grade was the greatest predictor of survival, with only $37 \%$ of G 3 patients surviving at 5 years.

The importance of depth of myometrial invasion and lymphovascular space invasion as prognostic factors for lymph node metastasis and tumor recurrence, and in negatively affecting survival has been recognized in different studies. ${ }^{19-21}$ Hachisuga et $\mathrm{a}^{22}$ have recommended that if severe lymphovascular space invasion is found, the patient, even if in the low-risk group, should undergo lymph-node dissection. In agreement with these studies, we also found that myometrial invasion (outer half) and the presence of frank lymphovascular space invasion were statistically significant variables associated with a decrease in diseasefree survival and overall survival. Also, in agreement with previous data, ${ }^{13}$ age was also a significant factor related to tumor recurrence and mortality. For each age increase of 1 year, the risk of tumor recurrence and death increases 1.05 and 1.07 times, respectively. It has been shown that cancer therapy varies with age, with the use of aggressive therapies declining with increasing age. ${ }^{13}$

Although pelvic and para-aortic lymphadenectomy is part of the FIGO staging system for endometrial cancer, a systematic review and meta-analysis concluded that there is no evidence that lymphadenectomy decreases the risk of death or disease recurrence compared with no lymphadenectomy in women with presumed stage I endometrial cancer. ${ }^{23}$ In our study, the performance of a lymphadenectomy did not confer advantages in disease-free survival and overall survival. Similar survival and recurrence rates were found to result from the laparoscopic approach and the traditional abdominal approach. Other studies have reported similar findings. ${ }^{24,25}$ As may be expected, the variables of incomplete surgical treatment and tumor remnant $>1 \mathrm{~cm}$ were both associated with a significant decrease in disease-free survival and overall survival. Moreover, prognosis clearly differed between the low-, intermediate-, and high-risk groups, with there being 31.4-times-higher risk of tumor 
recurrence and 28.3-times-higher risk of death for patients classified into the high-risk group compared with those in the low-risk category.

\section{Conclusion}

This single-center retrospective analysis confirms that FIGO stage and tumor grade are independent prognostic factors of disease-free survival and overall survival in patients diagnosed with endometrial cancer. The preoperative study is critical to define the group of patients who should undergo lymphadenectomy, depending on which is considered high or low risk. As shown, poorly differentiated tumors have a very unfavorable effect on survival and it is necessary to know this information before the patient is in the operating room. Outcome was also influenced by histopathologic tumor type, myometrial and lymphovascular space invasion, lymph-node involvement, age, and tumor remnants after surgery, although a larger study sample is probably needed to demonstrate the independent association of these variables with survival.

\section{Acknowledgment}

We thank Marta Pulido, MD, for editing the manuscript and providing editorial assistance.

\section{Disclosure}

The authors declare no conflicts of interest in this work.

\section{References}

1. Moxley KM, McMeekin DS. Endometrial carcinoma: a review of chemotherapy, drug resistance, and the search for new agents. Oncologist. 2010;15(10):1026-1033.

2. Westin SN, Broaddus RR. Personalized therapy in endometrial cancer: challenges and opportunities. Cancer Biol Ther. 2012;13(1):1-13.

3. Renehan AG, Tyson M, Egger M, Heller RF, Zwahlen M. Body-mass index and incidence of cancer: a systematic review and meta-analysis of prospective observational studies. Lancet. 2008;371(9612):569-578.

4. Sorosky JI. Endometrial cancer. Obstet Gynecol. 2012;120(2 Pt 1): 383-397.

5. Creasman WT, Odicino F, Maisonneuve P, et al. Carcinoma of the corpus uteri. FIGO 26th Annual Report on the Results of Treatment in Gynecological Cancer. Int J Gynaecol Obstet. 2006;95 Suppl 1: S105-S143.

6. Sorosky JI. Endometrial cancer. Obstet Gynecol. 2008;111(2 Pt 1): 436-447.

7. Malkasian GD Jr. Carcinoma of the endometrium: effect of stage and grade on survival. Cancer. 1978;41(3):996-1001.

8. Hirai M, Hirono M, Oosaki T, Hayashi Y, Yoshihara T, Matsuzaki O. Prognostic factors relating to survival in uterine endometrioid carcinoma. Int J Gynaecol Obstet. 1999;66(2):155-162.
9. Kosary CL. FIGO stage, histology, histologic grade, age and race as prognostic factors in determining survival for cancers of the female gynecological system: an analysis of 1973-1987 SEER cases of cancers of the endometrium, cervix, ovary, vulva, and vagina. Semin Surg Oncol. 1994;10(1):31-46.

10. Guntupalli SR, Zighelboim I, Kizer NT, et al. Lymphovascular space invasion is an independent risk factor for nodal disease and poor outcomes in endometrioid endometrial cancer. Gynecol Oncol. 2012;124(1):31-35.

11. Abeler VM, Kjørstad KE, Berle E. Carcinoma of the endometrium in Norway: a histopathological and prognostic survey of a total population. Int J Gynecol Cancer. 1992;2(1):9-22.

12. Fujimoto T, Nanjyo H, Fukuda J, et al. Endometrioid uterine cancer: histopathological risk factors of local and distant recurrence. Gynecol Oncol. 2009;112(2):342-347.

13. Goodwin JS, Samet JM, Key CR, Humble C, Kutvirt D, Hunt C. Stage at diagnosis of cancer varies with the age of the patient. J Am Geriatr Soc. 1986;34(1):20-26.

14. Li B, Wu LY, Li SM, Zhang WH, Zhang R, Ma SK. Multivariate analysis of prognostic factors in endometrial carcinoma. Ai Zheng. 2004;23(9):1085-1088. Chinese.

15. Steiner E, Eicher O, Sagemüller J, et al. Multivariate independent prognostic factors in endometrial carcinoma: a clinicopathologic study in 181 patients: 10 years experience at the Department of Obstetrics and Gynecology of the Mainz University. Int Gynecol Cancer. 2003;13(2): 197-203.

16. Hanson MB, van Nagell JR Jr, Powell DE, et al. The prognostic significance of lymph-vascular space invasion in stage I endometrial cancer. Cancer. 1985;55(8):1753-1757.

17. Milosevic MF, Dembo AJ, Thomas GM. The clinical significance of malignant peritoneal cytology in stage I endometrial carcinoma. Int $J$ Gynecol Cancer. 1992;2(5):225-235.

18. Reisinger SA, Staros EB, Mohiuddin M. Survival and failure analysis in stage II endometrial cancer using the revised 1988 FIGO staging system. Int Radiat Oncol Biol Phys. 1991;21(4):1027-1032.

19. Zaino RJ, Kurman RJ, Diana KL, Morrow CP. Pathologic models to predict outcome for women with endometrial adenocarcinoma: the importance of the distinction between surgical stage and clinical stage - a Gynecologic Oncology Group study. Cancer. 1996;77(6): $1115-1121$.

20. Mariani A, Dowdy SC, Cliby WA, et al. Efficacy of systematic lymphadenectomy and adjuvant radiotherapy in node-positive endometrial cancer patients. Gynecol Oncol. 2006;101(2):200-208.

21. Briët JM, Hollema H, Reesink N, et al. Lymphvascular space involvement: an independent prognostic factor in endometrial cancer. Gynecol Oncol. 2005;96(3):799-804.

22. Hachisuga T, Kaku T, Fukuda K, et al. The grading of lymphovascular space invasion in endometrial carcinoma. Cancer. 1999;86(10): 2090-2097.

23. May K, Bryant A, Dickinson HO, Kehoe S, Morrison J. Lymphadenectomy for the management of endometrial cancer. Cochrane Database Syst Rev. 2010;(1):CD007585.

24. Magrina JF, Mutone NF, Weaver AL, Magtibay PM, Fowler RS, Cornella JL. Laparoscopic lymphadenectomy and vaginal or laparoscopic hysterectomy with bilateral salpingo-oophorectomy for endometrial cancer: morbidity and survival. Am JObstet Gynecol. 1999;181(2): 376-381.

25. Holub Z, Jabor A, Bartos P, Eim J, Urbánek S, Pivovarniková R. Laparoscopic surgery for endometrial cancer: long-term results of a multicentric study. Eur J Gynaecol Oncol. 2002;23(4):305-310. 
OncoTargets and Therapy

\section{Publish your work in this journal}

OncoTargets and Therapy is an international, peer-reviewed, open access journal focusing on the pathological basis of all cancers, potential targets for therapy and treatment protocols employed to improve the management of cancer patients. The journal also focuses on the impact of management programs and new therapeutic agents and protocols on

patient perspectives such as quality of life, adherence and satisfaction. The manuscript management system is completely online and includes a very quick and fair peer-review system, which is all easy to use. Visit http://www.dovepress.com/testimonials.php to read real quotes from published authors.

Submit your manuscript here: http://www.dovepress.com/oncotargets-and-therapy-journal 